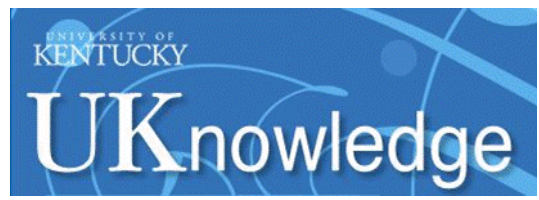

University of Kentucky

UKnowledge

Power and Energy Institute of Kentucky Faculty

Publications

Power and Energy Institute of Kentucky

$10-2018$

\title{
Power Utility Tests for Multi-MW High Energy Batteries
}

Oluwaseun M. Akeyo

University of Kentucky, ochichikeyo@gmail.com

Huangjie Gong

University of Kentucky, huangjie.gong@uky.edu

Vandana Rallabandi

University of Kentucky, vandana.rallabandi@uky.edu

Nicholas Jewell

$L G \& E$ and $K U$

Dan M. Ionel

University of Kentucky, dan.ionel@uky.edu

Follow this and additional works at: https://uknowledge.uky.edu/peik_facpub

Part of the Power and Energy Commons

Right click to open a feedback form in a new tab to let us know how this document benefits you.

\section{Repository Citation}

Akeyo, Oluwaseun M.; Gong, Huangjie; Rallabandi, Vandana; Jewell, Nicholas; and Ionel, Dan M., "Power Utility Tests for Multi-MW High Energy Batteries" (2018). Power and Energy Institute of Kentucky Faculty Publications. 27.

https://uknowledge.uky.edu/peik_facpub/27

This Conference Proceeding is brought to you for free and open access by the Power and Energy Institute of Kentucky at UKnowledge. It has been accepted for inclusion in Power and Energy Institute of Kentucky Faculty Publications by an authorized administrator of UKnowledge. For more information, please contact UKnowledge@lsv.uky.edu. 


\title{
Power Utility Tests for Multi-MW High Energy Batteries
}

\author{
Digital Object Identifier (DOI)
}

https://doi.org/10.1109/ICRERA.2018.8566920

\section{Notes/Citation Information \\ Published in 2018 7th International Conference on Renewable Energy Research and Applications (ICRERA).}

(c) 2018 IEEE Copyright Notice. "Personal use of this material is permitted. Permission from IEEE must be obtained for all other uses, in any current or future media, including reprinting/republishing this material for advertising or promotional purposes, creating new collective works, for resale or redistribution to servers or lists, or reuse of any copyrighted component of this work in other works."

The document available for download is the authors' manuscript version that is accepted for publication. The final published version is copyrighted by IEEE and available as: O. Akeyo, H. Gong, V. Rallabandi, N. Jewell and D. M. Ionel, "Power Utility Tests for Multi-MW High Energy Batteries," 2018 IEEE International Conference on Renewable Energy Research and Applications (ICRERA), Paris, 2018, pp. 1396-1399. doi:10.1109/ICRERA.2018.8566920 


\title{
Power Utility Tests for Multi-MW High Energy Batteries
}

\author{
Oluwaseun Akeyo ${ }^{1}$, Huangjie Gong ${ }^{1}$, Vandana Rallabandi ${ }^{1}$, Nicholas Jewell ${ }^{2}$, and Dan M. Ionel ${ }^{1}$, \\ ${ }^{1}$ SPARK Laboratory, ECE Department, University of Kentucky, Lexington, KY \\ m.akeyo@uky.edu, huangjie.gong@uky.edu,vandana.rallabandi@uky.edu, dan.ionel@uky.edu \\ ${ }^{2}$ LG\&E and KU, Louisville, KY Nicholas.Jewell@lge-ku.com
}

\begin{abstract}
This paper reviews the procedures, layouts and metrics described in the new test manual issued by the Electric Power Research Institute (EPRI), in order to determine the performance, functionality and equivalent models of a utility scale battery energy storage system (BESS). In this approach, the large battery unit is connected to the dc-link of a bidirectional power conversion system (PCS), which may be interfaced with either the utility grid or a load bank for the purpose of estimating the BESS operation and performance characteristics, some of which includes; available charge/discharge energy at rated power, continuous charge/discharge duration, battery ramp rate, and ac round trip efficiency (RTE). For the purpose of characterizing and verifying the functionalities of the utility sized BESS, the bidirectional converter is operated with different charge and discharge cycles relevant to each specification and the battery state of charge along with electrical measurements at the ac and dc side are monitored and recorded. Also, an electrical equivalent circuit for a utility scale battery unit was developed based on the 1MW/2MWh operational BESS at the LG\&E and KU E.W. Brown facility. This model was formulated using an improved method for estimating the battery cell parameters.

Index Terms-BESS, battery, energy storage, grid connected converter, battery modeling, Li-ion battery, performance testing.
\end{abstract}

\section{INTRODUCTION}

Maintaining a robust and resilient method of delivering electrical energy from distributed generation sources to end users is one of the major challenges the modern grid is expected to handle. Battery energy storage in both large and small scale are expected to help mitigate some of these challenges through frequency regulation, capacity/demand response, demand charge reduction, mitigating infrastructure investment in addition to improving the overall quality of electricity [1]. Performance characterization of energy storage technology is necessary as a means to effectively model the battery energy storage as its own system or part of a system.

The Electric Power Research Institute (EPRI) recently released an energy storage test manual aimed to support improved understanding of large scale energy storage system technical characteristics relevant to utility requirements [2]. This manual defines consistent procedures and metrics to objectively compare and track the performance of a battery energy storage system (BESS). This study reviews the important tests described by the EPRI test manual for BESS, with detailed implementation of the prioritized procedures.

Recent BESS related researches have been focused on the characterization and estimation of parameters for a single battery cell equivalent circuit [3]-[5]. This research uses an improved pulse discharge battery cell characterization method that accounts for the fraction of battery current initially flowing through the capacitors of the RC branches of the equivalent circuit as opposed to conventional approaches, which typically assume the capacitor is saturated in its RC zero state voltage computation.

This study also presents an approach for characterizing utility scale BESS with multiple cells connected in series and parallel. The parameters for the equivalent circuit of a large BESS were computed based on the $1 \mathrm{MW} / 2 \mathrm{MWh}$ operational BESS at the LG\&E and KU E.W. Brown facility.

\section{Setup For BAttery Energy Storage System}

The BESS may be divided into two major sections; the energy storage unit and the power conditioning system. The energy storage unit consists of the battery unit, which is a connection of multiple cells in series and parallel; the battery management system, which includes the HVAC for temperature regulation and fire suppression system. The power conditioning device includes the bidirectional dc/ac converter, utility power transformer, ac and dc circuit breakers and the overall system management (Fig. 1a).

In this approach, the BESS may be disconnected from the grid during battery tests and directly coupled to a variable load bank capable of absorbing up to 1MVA energy at 5kVA steps (Fig. 1b). This configuration with an optional load bank allows effective testing of the BESS without disrupting the operation of the power grid.

\section{ReVIEW of EPRI BatTery Test Procedures}

The energy storage integration council (ESIC) at EPRI proposed multiple charge and discharge test cycles for characterizing utility scale BESS. These cycles may be use to define the functionalities, performance and verify manufacturer specifications such as available energy, charge/discharge duration, round trip efficiency and self-discharge rate. For the purpose of improving accuracy during tests, it is recommended that the BESS environmental enclosure is maintained at $23^{\circ} \mathrm{C}$ or manufacturer's recommended operating temperature and a minimum of 10 minutes rest time is allowed between charge and discharge cycles. 


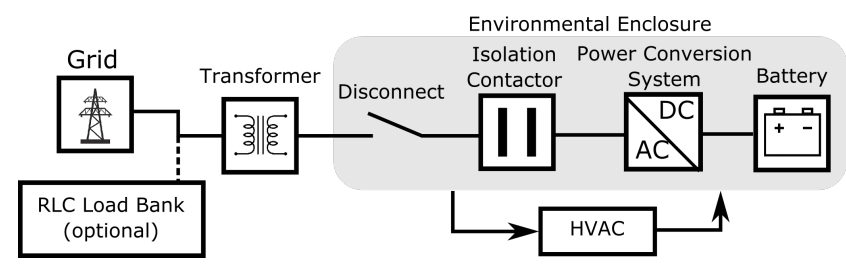

(a)

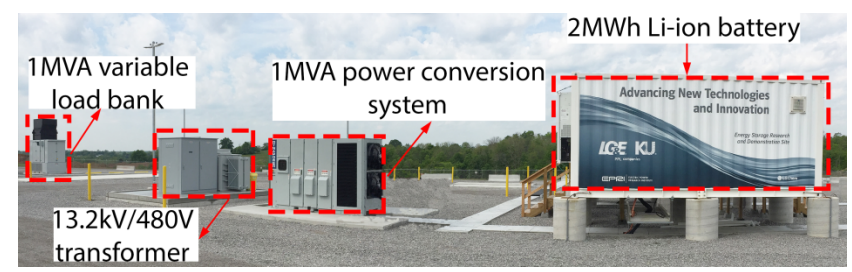

(b)

Fig. 1. (a) An example battery energy storage system (BESS) setup with the battery unit directly connected to the dc-link of the bidirectional converter The BESS may be isolated from the utility grid and connected to the available programmable load bank during the discharge tests, (b) the E.W. Brown LG\&E $\mathrm{KU}$ BESS facility rated for $1 \mathrm{MW} / 2 \mathrm{MWh}$. The two battery container units, one of which is obscured by the one shown in the image, are each rated $1 \mathrm{MWh}$ and connected to the de link of the converter. Also, the site includes a SCADA facility, which is not shown.

\section{A. Available BESS Energy}

The amount of energy a BESS can provide or absorb is dependent on the energy rating of the battery unit and each component of the system for adequate operation. For the purpose of defining the available energy for large BESS, the EPRI test manual recommends charging and discharging it between the maximum and minimum SOC limits at different power ratings, while ensuring a maximum of one complete test cycle per day (Fig. 2). The available charge/discharge energy may be computed as:

$$
E_{c h g(d c h g)}=\frac{1}{n} \sum_{1}^{n}\left(E_{C n(D n)} \pm E_{A C n(A D n)}\right),
$$

where, $E_{c h g}$ and $E_{d c h g}$, are the available charge and discharge energy, respectively; $n$ is the number of complete cycles considered; $E_{D n}$ and $E_{C n}$, is the energy at the point of common coupling (PCC) calculated as an integral of the metered power for $n$ discharge and charge cycle, excluding energy for auxiliary loads, respectively; $E_{A D n}$ and $E_{A C n}$, is the summation of energy from all auxiliary devices required to maintain BESS operation during $n$ discharge and charge cycles, respectively.

\section{B. Charge/Discharge Duration}

The rated continuous charge duration for large BESS described by the EPRI test manual is the amount of time required to charge it from minimum SOC to maximum at rated power and vice versa for discharge duration. The real power schematic in Fig. 2 at unity power factor may be used to determine the battery charge duration, considering only the duration, where the charge/discharge power is within $\pm 2 \%$ of the rated power.

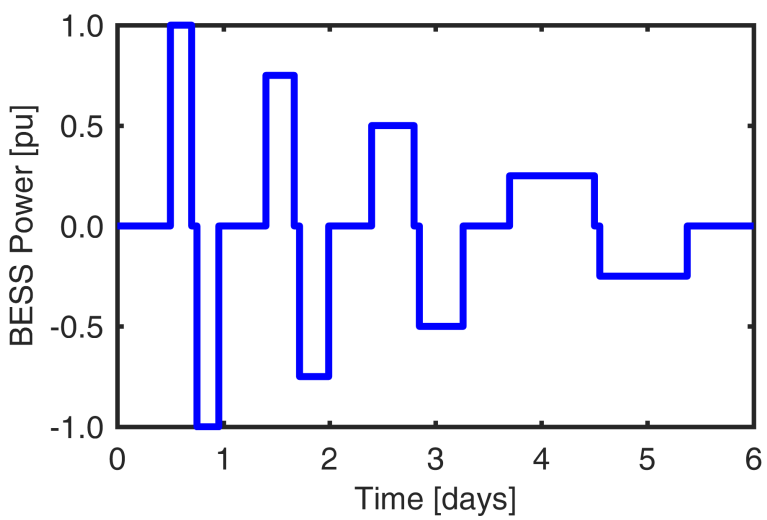

Fig. 2. The schematic representation of the BESS real power duty cycle for determining operational and performance characteristics recommended by the EPRI test manual for large BESS. The BESS was charged/discharged at $100 \%, 75 \%, 50 \%$, and $25 \%$ of its rated power in other to verify manufacturer specifications.

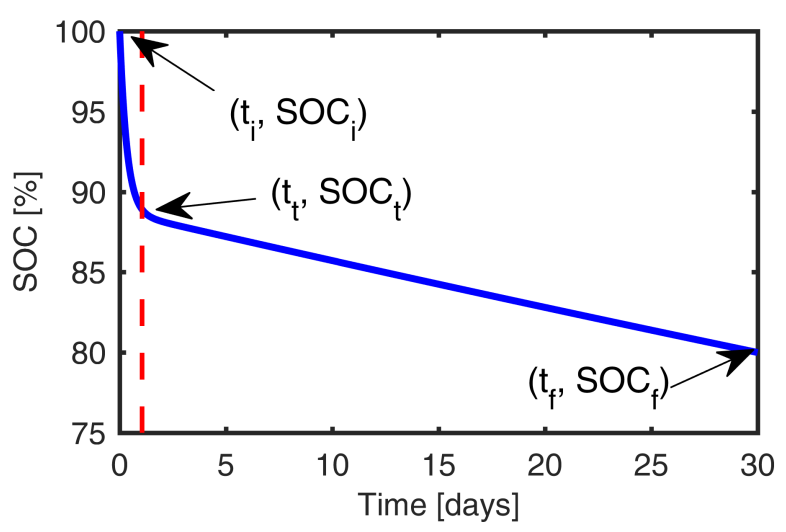

Fig. 3. The schematic representation for an example SOC variation due to self discharge based on concept described in the EPRI test manual. The self discharge rate is highest at the first $24 \mathrm{~h}$ after full charge and then tapers off to a lower somewhat constant rate.

\section{BESS Round Trip Efficiency}

The round trip efficiency (RTE) of an energy storage is the fraction of the energy used to charge the BESS that is available for dispatch. Apart from providing information concerning the energy available, knowledge of the RTE can also be used to monitor the performance of the BESS as well as its individual components. The percentage RTE may be computed as:

$$
R T E(\%)=\frac{1}{n} \sum_{1}^{n} \frac{E_{D n}-E_{A D n}}{E_{C n}+E_{A C n}} \cdot 100 .
$$

When calculating the system RTE at the dc bus, $E_{A C n}$ and $E_{A D n}$ should be represented as the summation of energy from all auxiliary devices on the battery unit alone required for effective BESS operation during charge and discharge, respectively. 


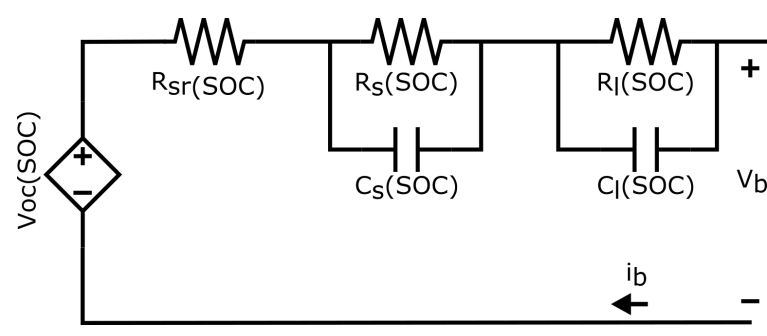

Fig. 4. An equivalent circuit diagram for a single battery cell. The battery characteristics may also be defined as a function of the cell temperature, number of charge and discharge cycles, self-discharge and cell state of health.

\section{Self-Discharge Rate}

The phenomenon, where the internal chemical reactions within a battery unit causes a reduction in its stored charge without any connection between its terminals is know as selfdischarge. The knowledge of the self-discharge rate (SDR) for large scale BESS will provide the utility companies information regarding the amount of charge energy available in the battery and the ability to schedule charge/discharge cycle for maximum RTE.

The SDR for large BESS may be classified into transient $\left(S D R_{t}\right)$ and long-term $\left(S D R_{L T}\right)$ SDRs. In order to estimate these values, the EPRI test manual recommends charging the BESS to maximum SOC and leaving it in shutdown mode for at least 7 days while monitoring its SOC (Fig. 3). The transient period refers to the partly exponential decay period in the battery SOC at the beginning of the test, where the SDR is maximum. The BESS SDR may also be computed by discharging it to its minimum SOC after the transient and longterm SDR period and recording the Watt-hour (Wh) discharge at the dc link. The expression for the transient SDR using the both methods is given as:

$$
S D R_{t}=\frac{S O C_{i}-S O C_{t}}{t_{t}-t_{i}}=\frac{W h_{i}-W h_{t}}{W h_{i} * t_{t}}
$$

where $t_{i}$ and $t_{t}$, are the test start time and intermediate transient time, respectively; $S O C_{i}$ and $S O C_{t}$, are the battery SOC corresponding to times $t_{i}$ and $t_{t}$, respectively; $W h_{i}$ and $W h_{t}$, represent the watt-hours discharge before the test and after the transient discharge, respectively. The value for $S D R_{L T}$ is computed over the $t_{t}$ and the end of analysis time, $t_{f}$. It is recommended to repeat the test for variations of $S O C_{i}$ for the battery full characterization.

\section{EQUiVAlENT BATTERY MODEL FOR UTILITY SCALED SYSTEMS}

A battery cell may be modeled as a controllable voltage source $\left(v_{o c}\right)$ connected in series with variable resistance $\left(R_{s r}\right)$ and multiple parallel $\mathrm{RC}$ branches $\left(R_{s}, C_{s}, R_{l}, C_{l}\right)$, whose characteristics vary with the cell physical and chemical properties. (Fig. 4). For the purpose of determining the parameter variations of a battery cell equivalent circuit, the cell is pulse discharged from maximum SOC to minimum, and the terminal voltage, $v_{b}$ variation at each open circuit recorded and analyzed. $v_{b}$ during discharge may be expressed as:

$$
v_{b}(t)=v_{o c}-i_{b} R_{s r}-v_{R C}(t),
$$

where, $v_{o c}$, is the battery open circuit voltage; $i_{b}$, is the battery output current; $v_{R C}$, the voltage across all the $\mathrm{RC}$ branches and $t$, the discharge duration. The conventional approach assumes all the capacitors are fully charged after each pulse and consequently, $i_{b}$ flows through the resistances alone. However, this is not always true, since the large capacitor $\left(C_{l}\right)$, requires current flow for a significant time before it becomes fully charged. Allowing the capacitors to become fully charged for each pulsewould necessitate large pulse widths, owing to the large time constants, thereby leading to a reduction in the amount of SOC points analyzed.

According to Kirchoff current law, $i_{b}$ is the total amount of current flowing through both the resistance and capacitor in any instance of time. Therefore, the current flowing through the resistor at the analyzed SOC may be represented as an unknown fraction of $i_{b}$. The zero state response of the RC branch voltage, $v_{R C 0}$, when the cell terminal is open circuited may therefore be expressed as:

$$
v_{R C 0}(t)=k_{1} i_{b} R_{s} e^{-\frac{\Delta t}{R_{s} C_{s}}}+k_{2} i_{b} R_{l} e^{-\frac{\Delta t}{R_{l} C_{l}}},
$$

where, $\Delta t$, is the duration of open-circuit; $k_{1}$ and $k_{2}$ represent the fractions of battery current, $i_{b}$, flowing through the resistor in each $\mathrm{RC}$ branch before the open-circuit.

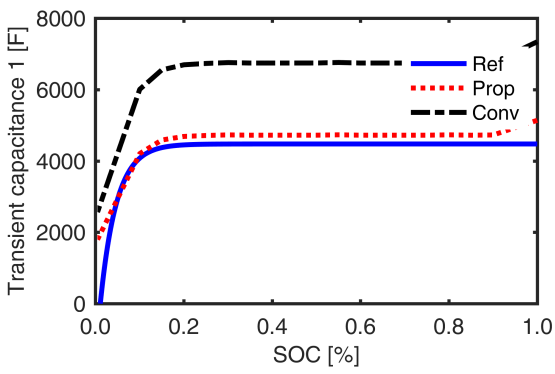

(a)

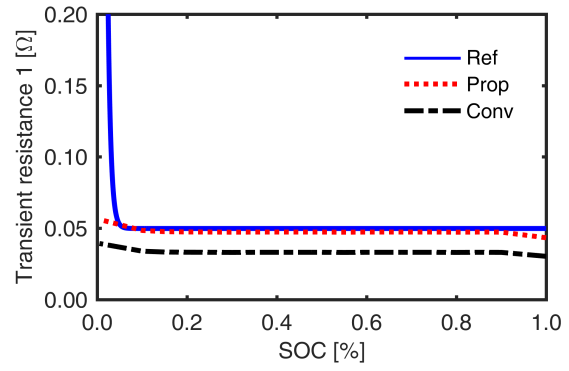

(b)

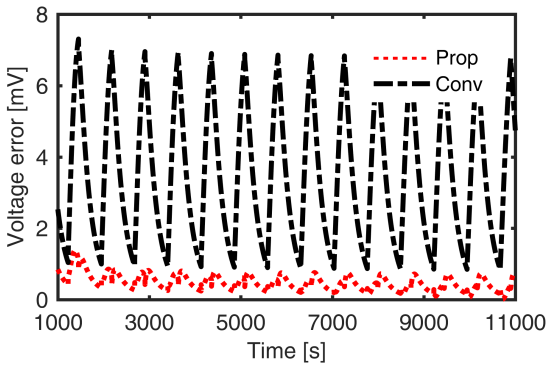

(c)

Fig. 5. Reference (Ref) and estimated parameters for a single battery cell using the conventional (Conv) and proposed (Prop) method showing: the large transient capacitance (a), the large transient resistance (b), and the voltage error relative to reference battery (c). The results illustrate the advantage of the proposed method. 


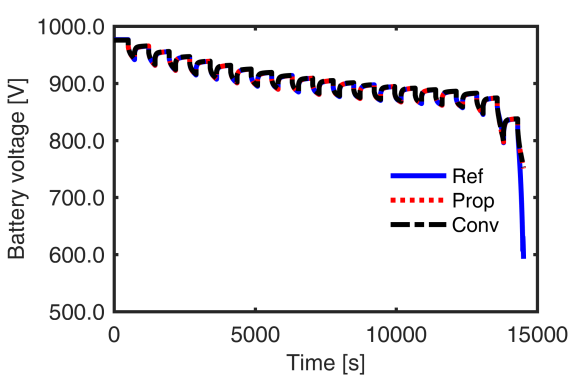

(a)

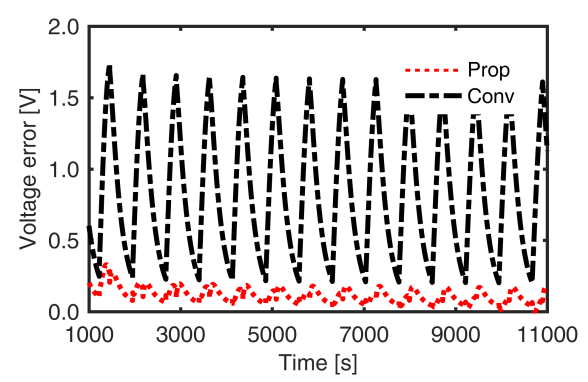

(b)

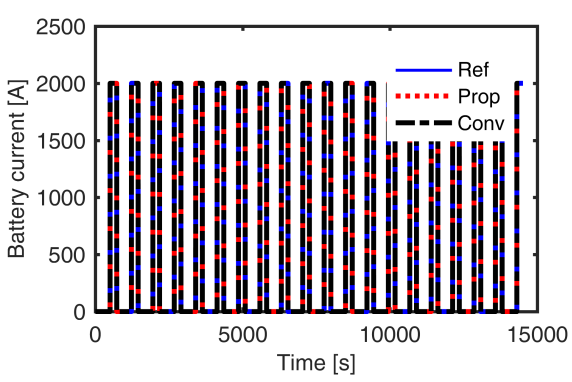

(c)

Fig. 6. Simulation results for a pulse discharged utility scale battery unit showing: the battery terminal voltage variation for actual and estimated battery models (a), the estimated voltage error for the large scale battery (b), and the battery dc output current (c).

For this study, in order to demonstrate the accuracy of the proposed method, the parameters of a reference cell model from [6] were used to develop an equivalent battery cell. The battery was pulse discharged at 5\% SOC intervals with a $851.4 \mathrm{~mA}$ constant current, leaving the cell open circuited for 500s after each pulse. The cell $v_{b}$ described in (4) was analyzed and the voltage across the RC components was curve fit, then the two term exponential expression obtained was compared with (5) for multiple values of $k_{1}$ and $k_{2}$, for the purpose of estimating the values of the RC components.

The values of $k_{1}$ and $k_{2}$, for which the minimum rms error in terminal voltage was achieved were selected, leading to an increase in the accuracy, particularly of the large transient capacitor and resistance estimate as compared to the conventional approach, where the values of $k_{1}$ and $k_{2}$ are assumed to be unity (Fig. 5). Some approaches use optimization algorithms for an estimate of all the parameters of the equivalent circuit [3], while in the proposed approach, only $k_{1}$ and $k_{2}$ need to be determined thus. Utility scale BESS may also be characterized by pulse discharging it from maximum to minimum SOC. In this approach, the inverter is operated at unity power factor and the real power output is regulated such that the battery outputs a constant current during each pulse, then the battery terminal voltage during open circuit is analyzed.

For this study, an equivalent battery unit with multiple reference cells connected in series and parallel was developed. Each component is represented as the series and parallel combination of the reference cell and given as:

$$
R_{u t}=S \cdot\left(\frac{1}{R_{c}} \cdot P\right)^{-1}, \quad C_{u t}=P \cdot\left(\frac{1}{C_{c}} \cdot S\right)^{-1},
$$

where, $R_{u t}, R_{c}, C_{u t}$ and $C_{c}$, are the unit and cell resistances and capacitances, respectively; $S$ and $P$, are the numbers of cells in series and parallel, respectively. The proposed method provided an $87.65 \%$ percent decrease in the rms voltage error relative to the conventional method when multiple cells of the reference circuit were connected to form an equivalent $2 \mathrm{MWh}$ BESS (Fig. 6).

\section{CONCLusion}

This paper summarizes the procedures and techniques recommended by the electric power research institute, EPRI energy storage integration council for determining the performance and functionality of utility scale BESS and proposes a new method for characterizing a battery unit. Utility companies may adopt these techniques and approaches for multiple benefits including; estimation of the available energy in order to effectively dispatch the BESS for peak shaving and peakshifting operation, computation of the system RTE at multiple points in order to monitor the performance of the battery unit and its components and the design of an equivalent model to efficiently represent the BESS as part of the electric grid.

The results show that for the examples considered, and assuming the battery unit is the exact representation of the equivalent circuit, an accuracy of up $99.9 \%$ is possible. Studies on parameter variation between multiple cells within a single battery unit is the subject of ongoing research.

\section{ACKNOWLEDGMENT}

The support of University of Kentucky, the L. Stanley Pigman endowment, of the SPARK Laboratory, Power and Energy Institute of Kentucky (PEIK), and of LG\&E and KU is gratefully acknowledged.

\section{REFERENCES}

[1] F. Blaabjerg and D. M. Ionel, Renewable Energy Devices and Systems with Simulations in MATLAB and ANSYS. CRC Press, 2017.

[2] Energy Storage Integration Council (ESIC) Energy Storage Test Manual. EPRI, Palo Alto, CA: 2017. 3002011739.

[3] A. Biswas, R. Gu, P. Kollmeyer, R. Ahmed, and A. Emadi, "Simultaneous state and parameter estimation of li-ion battery with one state hysteresis model using augmented unscented kalman filter," in 2018 IEEE Transportation Electrification Conference and Expo (ITEC), June 2018, pp. 1065-1070.

[4] B. Xia, X. Zhao, R. de Callafon, H. Garnier, T. Nguyen, and C. Mi, "Accurate lithium-ion battery parameter estimation with continuoustime system identification methods," in 2016 IEEE Energy Conversion Congress and Exposition (ECCE), Sept 2016, pp. 1-8.

[5] A. M. Bizeray, J. H. Kim, S. R. Duncan, and D. A. Howey, "Identifiability and parameter estimation of the single particle lithium-ion battery model," IEEE Transactions on Control Systems Technology, pp. 1-16, 2018.

[6] M. Chen and G. A. Rincon-Mora, "Accurate electrical battery model capable of predicting runtime and i-v performance," IEEE Transactions on Energy Conversion, vol. 21, no. 2, pp. 504-511, June 2006. 